\title{
LA IRRUPCIÓN DEL BIOCENTRISMO JURÍDICO. LOS DERECHOS DE LA NATURALEZA EN AMERICA LATINA Y SUS DESAFÍOS
}

\section{The Irruption of Legal Biocentrism.Rights of Nature in Latin America and its Challenges}

\author{
JAVIER ALFREDO MOLINA-ROA ${ }^{1}$ \\ ${ }^{1}$ Abogado con Maestría en Derecho de los Recursos Naturales de la Universidad Externado de Colombia, \\ e investigador del Grupo de Derecho del Medio Ambiente de la Universidad Externado de Colombia.
}

E-mail: javierm1272@yahoo.es

Recibido: 10 de Septiembre de 2016

Aceptado: 23 de Noviembre de 2016

\section{Resumen}

En el presente texto se analizan las nuevas normas sobre reconocimiento y protección de los derechos de la naturaleza que han sido promulgadas en América Latina, así como la fuerte influencia del denominado biocentrismo en la construcción del nuevo articulado constitucional y legal que persigue un cambio radical en la gestión del patrimonio ecológico de países como Ecuador y Bolivia, además de considerar el impacto de estas disposiciones en el sistema normativo tradicional latinoamericano, heredero del derecho europeo. Igualmente se describen algunas manifestaciones jurídicas precedentes que han tenido como objetivo la protección de los sistemas naturales y de los seres vivos no humanos y han influido el nuevo paradigma constitucional ecuatoriano, como es el caso de las ordenanzas municipales en los Estados Unidos que confieren derechos propios a los sistemas naturales. El texto también refiere las leyes ecológicas nazis,como un importante precedente en materia de protecciónde la naturaleza, ligado directamente a la ideología nacionalsocialista. La protección jurídica de la naturaleza y los animales en la jurisprudencia colombiana también es analizada. Finalmente el artículo analiza los retos que implica en Latinoamérica la aplicación y efectiva puesta en obra de las nuevas disposiciones que confieren derechos a la naturaleza y la elevan a la categoría de nuevo sujeto jurídico.

Palabras claves: Constitución, Leyes, Biocéntrico, Antropocentrismo.

\section{Abstract}

This paper analyzes the new laws enacted in Latin America that recognize and protect the rights of nature, as well as the strong influence ofthe biocentric theory in the construction ofthese new laws as a radical change in the management of the ecological issues of countries like Ecuador and Bolivia, like as impact of these provisions on the traditional regulatory system in Latin America, based on european law. Also some legal demonstrations about protection of natural systems and non human living beings that had influence in the new constitutional paradigm in Ecuador are described, as the case of municipal ordinances in the United States conferringrightsto natural communities and ecosystems. Also this paper refers the nazi environmental laws, like a important precedent in environmental protection directly linked with the nationalsocialist ideology. The legal protection of nature and animals in Colombian jurisprudence is also analyzed. Finally, the article discusses the challenges in Latin America forthe enforcement of the new provisions that consider nature like a new legal subject.

Keywords: Constitution, Laws, Biocentric, Anthropocentrism. 


\section{INTRODUCCIÓN}

Uno de los discursos predominantes actualmente en América Latina es el de la decolonización. Los nuevos movimientos sociales y políticos de varios países del Cono Sur, como las confederaciones indígenas en el Ecuador y las alianzas de campesinos e indígenas en Bolivia, buscan establecer total distancia con el pensamiento occidental o eurocéntrico, así como acabar con las clásicas relaciones de dominación entre las naciones desarrolladas y los estados emergentes del Tercer mundo. En la primera parte del texto, se plantea como una de las más importantes manifestaciones de este nuevo paradigma latinoamericano, el nacimiento y consolidación de un pensamiento biocéntrico, que se ve materializado en formas jurídicas, lo cual implica consideración moral, plena dignidad y reconocimiento de derechos a los componentes no humanos de la Tierra y a los sistemas vivos, independientemente de su utilidad para la supervivencia y propósitos del hombre. El texto describe como la naturaleza, en su versión integradora de Pachamama o Madre Tierra, propia de los pueblos indígenas de los Andes ha sido consagrada en el orden constitucional y legal, como sujeto jurídico con derechos propios, lo cual constituye un nuevo modelo de pensamiento que rescata la cosmovisión propia de los pueblos originarios de los Andes y genera un nuevo status ético y legal para los no humanos.

La segunda parte del artículo describe algunos antecedentes de estas normas progresistas, las cuales no son producto único del nuevo quehacer jurídico latinoamericano, sino que han sido precedidas de otras manifestaciones normativas, como son las leyes del régimen nacionalsocialista alemán sobre protección de la naturaleza, los bosques y los animales, las cuales tuvieron un fuerte sustento en el pensamiento romántico y naturalista germano, sin que guarden relación con el movimiento biocéntrico latinoamericano, el cual tiene sus orígenes en sociedades y culturas muy diferentes y con cosmovisiones distintas. Otros antecedentes normativo de corte biocéntrico, los constituyen las ordenanzas municipales de los Estados Unidos, que han reconocido derechos a los ríos, los arroyos y los humedales, valiéndose de una interpretación amplia de la Constitución norteamericana y la Constitución Política alemana que desde el año 2002 reconoce la dignidad de hombres y animales creando un paradigma dentro del marco constitucional de la Unión Europea. El texto igualmente refiere las manifestaciones jurídicas recientes en Colombia, donde a través de varias sentencias proferidas por los altos tribunales, se reconocen derechos a la naturaleza y también se consagran prerrogativas legales para los animales y las plantas, constituyéndose en piezas jurisprudenciales de avanzada producto del activismo judicial, que busca marcar una nueva tendencia de interpretación jurídica, en el marco de una legislación antropocentrista.

Por último se plantean algunos de los principales desafíos a los que debe responder el biocentrismo jurídico latinoamericano, el cual opera en el marco de un enfoque económico extractivista, estrechamente ligado a los objetivos políticos de gobiernos progresistas, obligados a responder de manera eficaz a las demandas de emancipación de los pueblos indígenas y campesinos y a los eternos reclamos de redistribución de la renta, inclusión y reconocimiento de la diversidad cultural, pero que deben enfrentar fuertes contradicciones a la hora de aplicar las nuevas normas ecológicas, bajo el actual modelo de producción y desarrollo que sostiene la economía y el bienestar de estos países.

\section{EL DESAFÍO BIOCÉNTRICO AL ORDEN JURÍDICO TRADICIONAL}

\author{
"..La naturaleza necesita de nosotros para \\ proseguir su proyecto..." Hubert Reeves
}

La ruptura con el pensamiento jurídico de corte eurocentrista está consolidada. La naturaleza es el nuevo sujeto de derechos del siglo XXI. Cientos de años de discusiones filosóficas, éticas y legales sobre estas particulares prerrogativas jurídicas han llegado a un punto de quiebre en América Latina. Lo paradójico es que este importante avance no se ha gestado precisamente en las aulas de las tradicionales universidades europeas y norteamericanas y en los centros de conocimiento del Primer mundo, cuna de los discursos jurídicos dominantes (Bordieu \& Wacquant 2001, Bonilla 2015) sino en las montañas de los Andes. El nuevo destinatario de derechos no es una minoría, ni una raza, ni un colectivo humano que por sus características, ideología,país de origen, orientación sexual o política merezca una protección jurídica reforzada o especial; en este caso se trata de una entidad omnipresente, sostén de la vida en el planeta y garante de la sobrevivencia de la especie humana. La naturaleza, entendida como el conjunto de interacciones entre los sistemas vivos y elementos físicos y bióticos en un territorio, ha sido elevada a la categoría de sujeto que tiene prerrogativas jurídicas, reconocidas en los ordenamientos legales superiores, las cuales pueden ser invocadas y protegidas a través de diversas acciones judiciales.

Sin embargo cabe preguntarse cuál ha sido el motivo impulsor de este nuevo paradigma en países en vía de desarrollo, que enfrenta al Derecho y lo obliga a reexaminar algunos de los principios y fundamentos que han orientado la creación y aplicación de normas durante siglos. El 
pensamiento dominante siempre ha reconocido y aceptado el señorío del hombre sobre la naturaleza sin discutir este principio, pilar de la dogmática jurídica y cimiento inamovible de los sistemas legales basados en el pensamiento occidental (Zaffaroni 2011). No obstante, una nueva interpretación y relegitimación de la naturaleza como sostén de la vida y de la especie humana, no doblegada a la dinámica globalizadora, surge con fuerza desde el tercer mundo y sienta un precedente normativo que en últimas constituye uno de los mayores desafíos al orden legal imperante. La naturaleza como sujeto jurídico, no puede seguir siendo víctima de la lógica capitalista y del afán de consumo contemporáneo; sus derechos son equiparables a los de cualquier ser humano y este reconocimiento no se queda en el papel, sino que es puesto en obra y materializado a través de fallos judiciales, como se ha podido comprobar en el caso ecuatoriano (Súarez 2012), donde mediante la aplicación directa de los principios constitucionales, se han suspendido proyectos mineros, pesqueros y de infraestructura, debido a la vulneración de los derechos de la naturaleza consagrados en los artículos 71 y 72 de la Constitución de ese país ${ }^{1}$.

Esta nueva visión de lo ecológico y del papel no preponderante de la especie humana dentro de la dinámica natural, trasciende el clásico enfoque basado tempranamente en la filosofía platónica con refuerzo cartesiano y en el utilitarismo tan pregonado por los planificadores y economistas clásicos, donde la explotación racional y mecánica de los recursos naturales, se basa en el principio de Desarrollo Sostenible, moderno paliativo que bajo criterios de protección ambiental justifica la apropiación social y el dominio de los sistemas naturales. Sin embargo, para las nuevas tendencias políticas y jurídicas que emergen en medio de la ola globalizadora, el medio ambiente ya no sería un cúmulo de aguas, bosques, suelo, aire y biodiversidad cuyo aprovechamiento se legitima a través de normas que se van modificando de manera constante, en muchos casos en la medida en que las necesidades de las políticas gubernamentales y de desarrollo lo exigen. En su

\footnotetext{
${ }^{1}$ El artículo 71 de la Constitución Ecuatoriana establece que la naturaleza o Pacha Mama, tiene derecho a que se respete integralmente su existencia y el mantenimiento y regeneración de sus ciclos vitales, estructura, funciones y procesos evolutivos. Asimismo establece que toda persona, comunidad, pueblo o nacionalidad podrá exigir a la autoridad pública el cumplimiento de los derechos de la naturaleza. El artículo 72 consagra el derecho de la Naturaleza a la restauración. Se pueden citar como fallos relevantes la Acción Constitucional 2011-0016 del 2011, control estatal de actividades mineras; Acción Constitucional de Protección 010-2011, afectación del río Vilcabamba; Acción de Protección 269-2012, construcción de vía en Islas Galápagos;Acción de Protección 166-2015, camaronera Marmeza; Acción de Protección 065-2015, caso del predio El Verdum. En todas ellas se reconocieron los derechos de la Naturaleza y se dictaron medidas de protección de estos derechos.
}

lugar, el nuevo enfoque biocéntrico que propende por la consideración moral de todos los seres vivos, especialmente los no humanos, independientemente de su utilidad para el hombre (Gudynas 2009), busca trascender el esquema dominante de gestión del patrimonio natural, proponiendo una ética con arraigo en un humanismo respetuoso de las dinámicas naturales y del valor propio de todos los seres que pueblan la Tierra y reconociendo humildemente un status no dominante a la raza humana dentro del entramado planetario (Devall \& Sessions 2004).

Estas nuevas categorías no obedecen a los postulados del conocimiento tradicional, donde la ciencia y la técnica se han transformado más en una ideología que se alimenta a sí misma, que en un elemento de liberación y transformación positiva del hombre y a su vez de la naturaleza (Habermas 1986). Para el orden antropocéntrico, los recursos naturales son elementos aprovechables, destinados instrumentalmente a suplir las necesidades de los seres humanos y procurarles bienestar, por lo que deben ser protegidos y conservados con ese fin, además de predecir, controlar y manipular sus fenómenos y manifestaciones, tal como lo ha reflejado claramente Habermas (1986), quien siguiendo a Marcuse, plantea que la dominación de la naturaleza a través de la ciencia y la técnica ha generado nuevas formas de dominación del hombre sobre sus congéneres: "la naturaleza comprendida y domeñada por la ciencia vuelve a aparecer de nuevo en el aparato de construcción y de destrucción que mantiene la vida de los individuos".

En contraposición a lo anterior y dentro de un orden biocéntrico, el mundo natural del que los humanos son solo una parte, sería una comunión de componentes esenciales dentro de un supraorganismo, que se encuentran en constante intercambio e interacción. La naturaleza, Pachamama, o Madre Tierra sería el contexto integrador que da vida y orden al planeta, donde los conceptos de medio ambiente y desarrollo sustentable pierden su relevancia y carácter dominante otorgados por unanimidad y poco discutidos desde las declaraciones de Estocolmo y de Río de Janeiro, en los años setenta y noventa del siglo pasado²; ya

${ }^{2}$ La Pachamama surge como uno de los elementos fundamentadores de la acción política del Estado, convirtiéndose en un valor ético y jurídico único que equipara el conocimiento occidental sobre el medio ambiente, con los saberes tradicionales indígenas y plantea una nueva forma de hacer política ambiental, mediante una fórmula jurídica que otorga la misma jerarquía a la visión ecológica de los pueblos indígenas y al concepto de orden natural tradicionalmente aceptado en el pensamiento eurocentrista. Ver GUDYNAS, Eduardo. La Pachamama: Etica Ambiental y Desarrollo. [en línea], Le Monde Diplomatique. Edición Boliviana, Año 3. No. 27, 2011, p.2. Disponible en: http:/hdl.handle.net/123456789/285. 
no se trataría de una naturaleza explotada sino de una naturaleza fraternal, que no es tratada como un objeto, sino como un sujeto en el cual se reconoce el hombre. (Habermas 1986).

Las normas constitucionales y las leyes progresistas que le otorgan preeminencia a la naturaleza y la convierten en un nuevo sujeto jurídico titular de derechos, irrumpen en un contexto jurídico heredero del derecho francés y del derecho romano (Bonilla 2015), donde se ha permitido que los elementos naturales hayan sido apropiados, utilizados, transformados, negociados y en muchos casos agotados (Cullinan 2011). Las aguas, los bosques, los animales, la biodiversidad de acuerdo con el ethos jurídico dominante, son cosas que pueden ser utilizadas sin que existan mayores límites que los que propenden por su conservación y aprovechamiento racional (Giraldo 2012). Su valor legal y social y por ende el deber de garantizar su existencia está dado únicamente por su utilidad para los fines humanos (Berry 1999). Esta típica separación y establecimiento de órdenes jerárquicos entre el mundo humano y no humano ha sido el punto de partida del pensamiento jurídico occidental (Graham 2003).

Sin embargo, el nuevo paradigma, fundamentado en gran parte en las cosmovisiones de los pueblos originarios latinoamericanos, predica un valor en sí mismos de todos los elementos de los sistemas naturales y rompe con el modelo jerárquico que regula la relación hombre-naturaleza, impuesto desde la Conquista y reforzado en la Modernidad (Gudynas 2010); el valor intrínseco de lo natural no depende en absoluto de los usos humanos, sino de su propia existencia y convivencia en el planeta, dentro de lo que algunos han denominado una nueva comunidad moral, de la cual la Tierra es el centro principal (Koons 2008). En concordancia con lo anterior, la nueva postura política y jurídica puede ser clasificada dentro del llamado ecologismo, el cual sostiene que una existencia sustentable y satisfactoria implica cambios radicales en la relación con el mundo natural no humano y en las formas de vida social y política (Dobson 1997). De aquí que los principios tradicionales del Derecho, propios del eurocentrismo y cuestionados por el giro epistemológico operado en varios países latinoamericanos (Caba \& García 2014), se vean revaluados en forma radical y las nuevas disposiciones consagren bienes jurídicos impensables hasta hace muy pocos años para el pensamiento legal tradicional; este sería el caso de los derechos de la naturaleza en la Constitución Política del Ecuador del año 2008 (Elbers \& Muñoz 2012, Rodríguez 2012) o las leyes bolivianas de 2010 y 2012 que consagran a la Madre Tierra como un sujeto colectivo de interés público y le otorgan los derechos a la vida, a la diversidad de la vida, al agua, al aire limpio, al equilibrio, a la restauración y a vivir libre de contaminación ${ }^{3}$. Este reconocimiento de fuerte contenido simbólico y en opinión de algunos, retórico, obligaría a los legisladores y a los jueces a tener en cuenta un tratamiento diferente para los animales, los árboles y los ríos, cuando estos llegan a ser considerados como sujetos de derecho, forzándolos a generar nuevas normas para su protección (Ost 1996).

Es importante resaltar el fuerte efecto simbólico derivado del reconocimiento jurídico expreso de la cosmovisión de los pueblos originarios de los Andes, que considera a la Pachamama o Madre Tierra como fuente de la vida y del orden natural y entidad superior integradora, la cual debe ser respetada para lograr el sumak kawsay quechua, principio de vida, de plenitud y guía de acción, extrapolado en la Constitución ecuatoriana bajo el concepto del Buen Vivir (Vanhulst \&Beling 2013)4. Es decir, se consagra a la naturaleza, como una entidad omnipotente y regeneradora, esencial para la supervivencia humana y la cohesión social y cultural, elemento que contribuye a guiar la acción de los nuevos estados latinoamericanos, en teoría libres de las ataduras colonialistas (Molina 2014).

\section{LOS ANTECEDENTES DEL BIOCENTRISMO JURIDICO}

Hay que admitir que las normas de corte biocéntrico que reivindican la primacía de los sistemas naturales, producto genuino del proceso de decolonización política y emancipación del orden eurocentrista, si bien son referentes claves en la esfera política y social latinoamericana contemporánea, no han sido las únicas manifestaciones jurídicas fuertes de protección de la naturaleza. Resulta bastante sorprendente, aunque ha sido claramente evidenciado por los historiadores, que el siglo XX tuvo como grandes adalides del conservacionismo radical, del respeto reverencial y la protección jurídica estricta de la naturaleza a los nazis. El romanticismo alemán, inspirador de múltiples

\footnotetext{
${ }^{3}$ Ver las Leyes 071 de 2010 y 300 de 2012, expedidas por la Asamblea Legislativa Plurinacionalde Bolivia, que además de consagrar los derechos de la Madre Tierra, establecen deberes específicos de los particulares y el Estado en relación con estos derechos, crean autoridades como la Autoridad Nacional de la Madre Tierra y la Defensoría de la Madre Tierra, que tienen por objeto garantizar y vigilar que se cumplan los principales postulados de estas normas.

${ }^{4}$ La Constitución ecuatoriana consagra el principio del sumak kawsay o su extrapolación moderna del Buen Vivir, como el hecho de saber vivir en armonía con los ciclos de la Madre Tierra, del cosmos, de la vida y de la historia, y en equilibrio con toda forma de existencia en permanente respeto. Sin embargoy de acuerdo con Vanhulst \&Beling 2013 (2013), lo que se ha hecho a través de la acción política es crear un nuevo horizonte de sentidopara enfrentar los retos del mundo contemporáneo, en especial la sustentabilidad, sin llegar a negar los fundamentos de la modernidad.
} 
manifestaciones culturales en el mundo entero, fue un movimiento precursor del amor hacia lo natural (Ferry, 1994). La herencia romántica y a la vez racista y nacionalista de pensadores del siglo XIX como Riehl y Klages, que consideraban la naturaleza como esencia de la nación y la identidad del pueblo germano y se manifestaban en contra de la degradación ambiental, la tala de bosques, la contaminación industrial y la desaparición de especies (Radkau 2008), inspiró las profundas y revolucionarias leyes ecológicas nazis; igualmente el concepto proteccionista y nacionalista del patrimonio natural que asimilaba la permanencia y fortaleza del pueblo germano a la salud y vitalidad de los bosques, fue uno de los pilares de la política forestal del régimen nacionalsocialista (Imort 2005). Las primeras leyes que reflejarían el profundo sentimiento ecológico de los nazis fueron promulgadas en el año 1933; prohibían el sacrificio innecesario de animales, la experimentación con ciertas especies, el maltrato animal, regulaban su uso en transporte y minería y erradicaban la vivisección bajo severas multas y hasta encarcelamiento en campos de concentración (Sax 2000).

En 1934 se expidió la Ley contra la Devastación de los Bosques, enfocada en el aprovechamiento sostenible de este recurso natural, permaneciendo vigente por más de cuarenta años. En ese mismo año fue promulgada la Ley de Conservación de la Pureza Racial de las Plantas, norma que en consonancia con las leyes racistas de la época, exigía eliminar semillas que pudieran producir árboles torcidos y buscaba desarrollar los mejores fenotipos para garantizar bosques saludables; siendo derogada solo hasta el año 1957 (Imort 2005). La Reichsnaturschutzgesetz, ley de conservación nacional, promulgada en 1935, en pleno ascenso del régimen totalitario nazi y considerada por un jurista como una pieza maestra del arte legislativo (Uekoetter 2006), consagraba un amplio rango de protección a la naturaleza y el paisaje, como soporte del espíritu nacional y de la nación alemana (Closmann 2005). A pesar de su novedad y el amplio alcance proteccionista y ecológico, varios investigadores han resaltado la existencia de antecedentes normativos de fuerte contenido ecológico desde principios del siglo $\mathrm{XX}$ en estados alemanes como Prusia y Baviera sobre conservación de bosques y espacios naturales, disposiciones que fueron hábilmente copiadas y transformadas por los ecologistas nazis, siguiendo los mandatos de la ideología dominante. También se ha estudiado el fuerte efecto propagandístico de estas leyes, su eficacia simbólica y su carácter ideológico, emparentado con la discriminación racial y la exclusión de los judíos de la vida nacional como criterios políticos dominantes en la época (Imort 2005).

Por otro lado, a la par que controlaban y reprimían con rigor la experimentación con animales y castigaban duramente el maltrato animal, los nazis realizaron terribles experimentos con judíos y prisioneros de guerra, que incluían mutilaciones, congelamiento, inoculación de virus y cirugías experimentales entre otros, los cuales por regla general concluían con la muerte de estas cobayas humanas (Rees 2007). También los planificadores de Hitler, dispusieron en su momento la germanización del paisaje en la Polonia ocupada, demoliendo pueblos, villas campestres y destruyendo parajes rurales, así como desplazando o exterminando a sus pobladores, con el objeto de implantar ambientes naturales similares a los existentes en suelo alemán (Wolschke-Bulmahn 2005).

En este escenario marcado por una ideología política radical, se vislumbra un efecto simbólico y unificador en el orden social y cultural alemán, generado a través de la evocación de un ente supranatural propio del imaginario colectivo, como fue el apego y amor a la naturaleza o terruño propio (Heimat). Igualmente el uso político de referentes de amplio reconocimiento y aceptación nacional, como la pureza de los bosques prístinos y la belleza de los bucólicos paisajes naturales, contribuyeron a reforzar la conciencia popular sobre la esencia de la nación y el espíritu germánicos y fueron un sostén importante de las leyes ecológicas del régimen nazi, que experimentó un auge del movimiento ecologista durante los mejores años de la dictadura.

Finalmente debe resaltarse que en Alemania ha persistido un fuerte espíritu ecologista apoyado en parte por la acción del Partido Verde (Dobson 1997), siendo uno de los primeros países europeos en consagrar un principio jurídico de protección de los no humanos en su Constitución (Sunstein2002). Es así como en el año 2002, se incluyeron las palabras "y animales", dentro una cláusula constitucional que obliga al Estado a respetar y proteger la dignidad de los seres humanos, lo cual se puede considerar como un antecedente del biocentrismo jurídico contemporáneo en una nación con una profunda conciencia ecológica, donde al menos el $80 \%$ de los alemanes apoyaban desde los años noventa la inclusión de la protección animal en la Constitución (Nattrass 2004).

Por otro lado y en fechas mucho más recientes, podemos encontrar en las ordenanzas municipales (municipal ordinances) de más de treinta localidades estadounidenses o townships (CELDF 2008), un activismo político y jurídico que hace del biocentrismo uno de sus principios de acción. La amenaza del fracking principalmente y la minería que se realizan por parte de empresas privadas, con los consiguientes impactos ambientales sobre las aguas, el suelo, los bosques y el aire, ha motivado la movilización de estas comunidades, que justificadas en el principio de democracia directa y haciendo una interpretación amplia y 
progresista del principio del autogobierno consagrado en la Constitución americana, han logrado que desde el año 2006 se aprueben normas municipales que le otorgan derechos a los sistemas y comunidades naturales, lo cual en últimas constituye un desafío al sistema de gobierno norteamericano y al poder de las corporaciones privadas (Molina 2014). En el marco de estas disposiciones, los nuevos sujetos de derechos pueden ser representados por cualquier persona en los estrados judiciales, quien puede pedir que se emitan órdenes de protección de estos elementos no humanos frente a amenazas de origen humano. Estos textos legales, de carácter plenamente vinculante, establecen que las comunidades naturales así como los ecosistemas, incluyendo humedales, arroyos, ríos, acuíferos y otros sistemas hídricos, poseen derechos inalienables a existir y florecer dentro de estos territorios, así como el derecho a que cualquier residente de estas comunidades pueda exigir la aplicación prioritaria de estas prerrogativas legales. La atribución de derechos, en este caso se hace de manera específica, de manera muy similar a la Constitución del Ecuador y las Leyes de la Madre Tierra en Bolivia, que consagran derechos puntuales de los sistemas naturales. Sin embargo y a pesar de los esfuerzos adelantados para la preservación del patrimonio natural local, estas comunidades constantemente enfrentan el riesgo de demandas en contra de las nuevas ordenanzas, pues sus detractores, que ya han logrado la anulación de varias disposiciones de esta clase, alegan que son contrarias a la Constitución americana y contravienen leyes de carácter federal, por lo que muchas de estas localidades no podrán impedir por mucho tiempo la explotación de gas y petróleo dentro de sus territorios, a menos que en palabras de Mary Margill (com. pers.), abogada y activista de esta fundación, se genere un fuerte movimiento social que obligue a muchos estados de la Unión Americana e expedir este tipo de normas. ${ }^{5}$

Información suministrada directamente al autor vía e mail por Mary Margill. En varios municipios de Antioquia (Colombia), entre ellos Urrao, Jardín, Támesis, Caicedo y Cañas Gordas, los Concejos Municipales con apoyo de la comunidad y los Alcaldes, sancionaron Acuerdos que prohibían la minería dentro de sus territorios por considerar que se podía afectar el patrimonio natural y bajo la premisa de que la Constitución Política les daba autonomía para proteger el patrimonio ecológico local. Sin embargo, estos actos jurídicos no resistieron el examen de las autoridades judiciales que prontamente declararon su nulidad, argumentando la falta de competencia de estas entidades territoriales para establecer prohibiciones a una actividad de utilidad pública e interés social. No obstante las sentencias C-123/14,C-035/16, C-273/16 y T-445/16 de la Corte Constitucional, han restituido y reforzado gran parte de esas competencias, obligando a las autoridades nacionales a realizar la consulta y concertación con los municipios antes de autorizar el desarrollo de proyectos mineros y facultando incluso a los municipios para prohibir la minería dentro de sus territorios.
Aprovechando su activismo ambiental y la experiencia ganada en los Estados Unidos, asesorando a múltiples comunidades en el diseño y promulgación de normas ecologistas, varios abogados y activistas del CELDF, acompañaron de manera directa a la Asamblea Constituyente de Montecristi en la redacción, discusión y redacción final de los artículos constitucionales que consagran derechos de la naturaleza en el Ecuador, teniendo como referente su trabajo en las municipalidades norteamericanas. ${ }^{6}$

\section{LAS MANIFESTACIONES DEL BIOCENTRISMO EN EL ORDENAMIENTO JURÍDICO COLOMBIANO}

Colombia se ha distinguido a nivel mundial por una Constitución orientada hacia la protección del medio ambiente, al punto que ha sido denominada la Constitución Ecológica por excelencia (Amaya 2002). Así mismo, su modelo de gestión ambiental pública, el llamado Sistema Nacional de Gestión Ambiental-SINA, creado por la Ley 99 de 1993, es reconocido por su concepto integrador y técnicas de gestión ambiental pluralista y participativa (Canal 2007). Sin embargo el medio ambiente no es consagrado como un derecho fundamental en la Constitución, logrando tal calificación por vía jurisprudencial y debido a su estrecha relación con los derechos fundamentales a la salud y a la vida, tal como ha sido expuesto en múltiples fallos de la Corte Constitucional, en especial la sentencia de unificación SU-067/93 donde el alto tribunal estableció que se trata de un derecho colectivo que puede ser protegido mediante la acción de tutela como derecho conexo.

En este orden de ideas y de acuerdo con el enfoque $y$ finalidad de sus principios fundantes, la Constitución colombiana se considera claramente de carácter antropocéntrico ${ }^{7}$. Así lo ha dejado claro la Corte en la

\footnotetext{
${ }^{6}$ Según un comunicado del propio CELDF, los delegados de la Asamblea Constituyente de Montecristi le pidierona esa organizaciónayuda con la redacción de un proyecto de norma sobre derechos de la naturaleza, basado en las ordenanzas desarrolladas y adoptadas por las municipalidades de los Estados Unidos. Ver Press Release: Ecuador Approves New Constitution: Voters Approve Rights of Nature. September 28th, 2008.Disponible en http:/ / www.celdf.org/article.php?id=302
}

${ }^{7} \mathrm{El}$ antropocentrismo se puede definir como la preeminencia otorgada por la filosofía, la ética y la economía al ser humano sobre los demás seres vivos del planeta Tierra; en ese orden de ideas las preocupaciones políticas, sociales y económicas se centran en garantizar la supervivencia y las necesidades de la raza humana sobre la base del dominio de la naturaleza. La gestión de los sistemas naturales apunta a su conservación y debida administración con fines de aprovechamiento, basado este en una racionalidad instrumental a fin de proveer alimento, energía, bienestary riqueza para el conjunto de la humanidad. Al respecto verTOCA TORRES Claudia. Versiones del Desarrollo Sostenible. [en línea]. Revista Sociedade e 
Ambiente y Sostenibilidad 2016 (6): 64-79

Revista del Doctorado Interinstitucional en Ciencias Ambientales

sentencia T-411/92, donde defiende el papel preponderante del ser humano en la Tierra y la subordinación de la acción del Estado a esta premisa:

“...Es a partir del ser humano, su dignidad, su personalidad jurídica y su desarrollo (artículos 10, 14 y 16 de la Constitución), que adquieren sentido los derechos, garantías y los deberes, la organización y funcionamiento de las ramas y poderes públicos", así como la defensa del ambiente, en tanto que éste es el entorno vital del hombre..."

En la sentencia C-058/94, la Corte reafirma el carácter antropocéntrico de la Constitución colombiana y justifica la dominación de la naturaleza así:

“...los seres humanos constituyen el centro de preocupaciones relacionadas con el desarrollo sostenible.

(...) Por eso, el mandato constitucional obliga a efectuar una utilización sostenible de tales recursos...".

En esta línea de pensamiento, con algunas variaciones poco relevantes, se ha mantenido la interpretación de la máxima norma jurídica en Colombia en relación con al papel dominante de los seres humanos frente al patrimonio natural. Tal posición, que podría ser llamada medioambientalista, se centra en un manejo administrativo de los problemas ambientales, bajo la creencia de que pueden ser resueltos sin ningún cambio fundamental en los valores o modelos de producción y consumo (Dobson 1997). No obstante y de manera intempestiva, la misma Corte en el año 2011 se atreve a hacer un ex cursus sobre este trascendental aspecto de la protección ambiental, al reflexionar sobre la naturaleza como un ente que puede ser sujeto de derechos, estando obligados el Estado y los particulares a garantizar su defensa y protección. En la sentencia C-632/11, la cual estudia la constitucionalidad de las medidas compensatorias del daño, exigibles dentro del procedimiento sancionatorio ambiental, la Corte se refiere a la necesidad de que el desarrollo económico: "no perturbe la naturaleza ni sus procesos esenciales; ello, sobre la base de considerar que la existencia de la especie humana, depende en gran medida del respeto incondicional al entorno ecológico."

La Corte continúa su análisis bajo los clásicos argumentos que defienden el principio del desarrollo sostenible y la protección del medio ambiente en virtud del interés general: sin embargo al determinar la naturaleza de las medidas compensatorias del daño ambiental manifiesta lo siguiente:

Cultura. Vol. 14, No. 1, enero-junio de 2011, Universidade Federal de Goiás. Disponible en www.redalyc.org/pdf/703/70320084019.pdf
ISSN: 2339-3122

Digital

“...las medidas compensatorias se inscriben, entonces, dentro de los mecanismos que el sistema jurídico ambiental ha instituido en defensa de los derechos de la naturaleza. Sobre este particular, es bueno recordar que el daño ambiental da lugar a la afectación de dos tipos de intereses: los personales y los naturales. Conforme con ello, el ordenamiento jurídico, al constituir los medios de defensa y garantía de los derechos, ha previsto la reparación a favor de las personas que puedan resultar afectadas en sus patrimonios y derechos (a través del resarcimiento propio de las acciones civiles -individuales y colectivas-), y la compensación o restauración para garantizar y asegurar los derechos de la naturaleza, concretamente, en relación con los derechos a mantener y regenerar sus ciclos vitales..."

Finalmente la Corte concluye sus argumentos biocéntricos catalogando al sistema natural como un sujeto de derechos, así:

"...es bueno considerar que en la actualidad, la naturaleza no se concibe únicamente como el ambiente y entorno de los seres humanos, sino también como un sujeto con derechos propios, que, como tal, deben ser protegidos y garantizados. En este sentido, la compensación ecosistémica comporta un tipo de restitución aplicada exclusivamente a la naturaleza...."

Causa sorpresa este giro jurídico que trastoca la línea jurisprudencial mantenida durante muchos años por el tribunal constitucional. Si bien, la misma Corte ha hecho alusión en múltiples sentencias a la fortaleza y bondades de una Constitución ecológica, no se había referido de manera tan explícita a la Naturaleza como un ente jurídico que posee derechos al igual que cualquier habitante del territorio colombiano. De esta forma y de acuerdo con las motivaciones del fallo de constitucionalidad, las medidas de compensación exigidas con motivo del daño ambiental constituyen una acción reparatoria de derechos conculcados en cabeza de un elemento de los sistemas naturales, ya sean las aguas, el aire, el suelo o inclusive la fauna, los cuales se encuentran en comunión dentro de un sujeto jurídico de mayor envergadura que posee vida, como es la Naturaleza ${ }^{8}$.

Creemos que este atípico fenómeno jurisprudencial puede

${ }^{8}$ Es posible aventurar que este postulado jurídico, bastante innovador dentro de la jurisprudencia colombiana, recoge ecos lejanos de la teoría Gaia, la cual considera a la Tierra como un organismo viviente complejo, con ciclos independientes de la acción humana, compuesta por múltiples elementos en constante interacción, donde el hombre sería un factor poco relevante desde el punto de vista sistémico pero disruptor en la continua dinámica de este ser vivo. Ver LOVELOCK, James. Las Edades de Gaia. $2^{\circ}$ ed. Barcelona, Tusquets, 1995 y LOVELOCK, James. La Tierra se Agota.Barcelona Editorial Planeta, 2011. 
Molina-Roa (2016)

tener una fuerte influencia de la corriente biocéntrica presente en otros países latinoamericanos y denota una interpretación progresista de la carta fundamental colombiana, visión que no ha pasado desapercibida en otras instancias judiciales, pues el Consejo de Estado, máximo tribunal de los asuntos administrativos, en sendas sentencias proferidas en los años 2012 y 2013 sentó un innovador y desconocido precedente en materia de derechos de los animales y las plantas en Colombia.

En el año 2012, la sección Tercera del Consejo de Estado, falló una demanda de nulidad relacionada con la reparación pecuniaria a los familiares de un hombre muerto por un toro en el matadero del municipio de Anserma-Caldas. En esta sentencia el magistrado ponente Enrique Gil Botero, aprovechó para llevar a cabo un análisis jurisprudencial sobre los discutidos derechos de los animales, concluyendo en consonancia con la postura biocéntrica, que estos poseen un valor intrínseco y por ende derechos propios:

“...En relación con el primer aspecto señalado, se pone de presente que las tesis contractualistas sobre la justicia vienen siendo reformuladas por las denominadas tesis comparativistas -en cabeza de teóricos de la justicia como AmartyaSen y Martha Nussbaum- que garantizan un mayor alcance de los principios de justicia social definidos en su momento por JhonRawls en su obra titulada "Teoría de la Justicia".

Conforme a esos planteamientos, los discapacitados, los animales y otros seres vivos tienen dignidad en sí mismos, porque al margen de que no manifiesten su voluntad en el denominado contrato social, sí son sujetos que tienen un propósito vital y finalidad en la existencia, tanto así que entran en relación directa y permanente con el ser humano. Sin esta fundamentación estructurada en la noción de "capacidades", no sería posible, por ejemplo, reconocer derechos fundamentales en cabeza de las personas jurídicas, tales como la garantía constitucional al debido proceso...

De allí que, según la menciona postura teórica, la dignidad insita al animal no permite asimilarlo a una cosa u objeto; por tal motivo, la responsabilidad derivada de los animales domésticos, domesticados o fieros no podría ser entendida como una especie de aquella que se refiere al hecho de las cosas. A contrario sensu, el principio de dignidad implícito en estos seres vivos haría que toda institución jurídica -incluida la responsabilidad extracontractual civil o del Estado- tuviera en cuenta esta condición, que serían fines en sí mismos, y que, por lo tanto, son susceptibles de ser titulares de derechos (v.gr. el derecho a no ser maltratado, el derecho a una muerte digna sin sufrimiento, entre otros).(...)

\section{El biocentrismo jurídico en América Latina}

Entonces, al margen de la discusión teleológica o fundamentalista sobre la dignidad humana (idealismo y racionalismo us cristianismo), así como de su contenido y alcance de principio basilar en el reconocimiento de la titularidad de derechos subjetivos, es pertinente reconocer valor propio en los animales $y$ otros seres vivos, y si bien resulta válido que el hombre en ocasiones emplee aquéllos para garantizar o mejorar su bienestar, o realizar actividades laborales o de recreación, lo cierto es que esta circunstancia no impide ni supone la negación de esa fundamentación filosófica que permite que la interpretación y hermenéutica del ordenamiento jurídico se efectúe bajo el reconocimiento de que son seres vivos dotados de valor propio $y$, por lo tanto, titulares de algunos derechos. .."9.

Siguiendo con esa línea jurisprudencial, en el fallo de fecha 26 de noviembre de 2013, nuevamente el magistrado Gil Botero, luego de un documentado análisis sobre teoría y dogmática jurídicas y filosofía del Derecho, manifiesta lo siguiente:

“....En criterio de esta Corporación, en los términos del literal c) del artículo 4 de la ley472 de 1998, existe un reconocimiento expreso por parte del legislador de derechos directos y autónomos a favor de los animales y las especies vegetales en nuestro territorio nacional. Esa finalidad, resulta incuestionable si se analiza la nueva normativa contenida en la ley 1638 de 2013, que prohíbe el uso de animales silvestres en circos o espectáculos circenses, es decir, de nuevo el legislador les asignó derechos a seres vivos distintos al ser humano, de manera concreta, los derechos a no ser maltratados y a no vivir en condiciones precarias. (...)

Así las cosas, para el legislador colombiano los animales y las especies vegetales (v.gr. los bosques, la Amazonía, los páramos, las fuentes y recursos hídricos, etc.) son sujetos de derechos y, por lo tanto, a través de la acción popular cualquier persona puede solicitar su protección actuando como agente oficioso de esas entidades, sin que se pueda afirmar que se trata de un derecho colectivo - subjetivo perteneciente a la sociedad; por el contrario, se trata del reconocimiento expreso por parte del Constituyente y del legislador colombiano de atribuir valor en sí mismos a los animales y a las especies vegetales, para lo cual, en cada caso concreto, el juez deberá elaborar un juicio de

${ }^{9}$ Consejo de Estado, Sala de lo Contencioso Administrativo, Sección Tercera, Subsección C Consejero ponente: ENRIQUE GIL BOTERO Bogotá D.C., veintitrés (23) de mayo de dos mil doce (2012) Radicación número: 1700123-3-1000-1999-0909-01(22592) 
ponderación o proporcionalidad entre los intereses en pugna u oposición.

En otros términos, no es necesario que los animales o las especies vegetales sean consideradas personas jurídicas o morales para que puedan comparecer a la administración de justicia en busca de que se protejan sus derechos reconocidos por la propia comunidad, ya que existen los mecanismos procesales constitucionales idóneos para garantizar el amparo de los respectivos derechos. (...) $)^{10}$

Como se puede detallar, el biocentrismo ha dejado huella propia en el ordenamiento jurídico colombiano y no puede ser desconocido en los futuros debates de los tribunales y del poder legislativo sobre el alcance de los nuevos derechos de los seres vivos no humanos. Una muestra reciente de esta nueva tendencia es la expedición de la Ley 1774 de 2016, que determina que los animales ya no son cosas sino "seres sintientes" y castiga penalmente el maltrato animal, consagrando otras prerrogativas orientadas hacia su protección y bienestar. Solo resta esperar que este movimiento, que cada vez adquiere más adeptos gracias en buena parte al dinamismo de las redes sociales, mute hacia mayores exigencias de protección de otros elementos de la naturaleza.

\section{LOS DESAFÍOS DEL BIOCENTRISMO JURÍDICO EN AMERICA LATINA}

Las cartas ya están echadas, la Constitución ecuatoriana y las leyes de la Madre Tierra bolivianas apenas inician su puesta en obra en materia de protección de los sistemas naturales. Los jueces ecuatorianos ya han dado los primeros pasos para garantizar estos nuevos derechos, a semejanza de la Corte Constitucional colombiana, que a partir del año 1992 produjo célebres fallos de orden ambiental, hoy referentes jurídicos a nivel nacional e internacional; la validez y pertinencia de los derechos de la Naturaleza y por ende de los animales, de los ríos y los páramos ya ha sido reconocida en la jurisprudencia colombiana. Sin embargo para todos es claro que el impulso biocéntrico de los operadores jurídicos no produce mayores efectos sin una voluntad política y un consenso social, que dote de plena

\footnotetext{
${ }^{10}$ Consejo de Estado, Sala de lo Contencioso Administrativo, Sección Tercera, Subsección C Consejero ponente: ENRIQUE GIL BOTERO Bogotá, D.C., veintiséis (26) de noviembre de dos mil trece (2013) Número de Radicación: 25000-23-24-000-2011-00227-01(AP). Este último fallo, al estilo de las ordenanzas norteamericanas dispone que cualquier persona puede exigir la protección de los derechos de los animalese incluso los delas plantas, los ríos y los páramos a través de la Acción Popular, mecanismo constitucional de defensa de derechos de amplia utilización en Colombia.
}

exigibilidad estas prerrogativas constitucionales y legales y las llene de contenido.

Lo que se ha visto inicialmente en el caso de Bolivia es la estructuración de nuevos organismos gubernamentales encargados de desarrollar los postulados biocéntricos. En el año 2012 se puso en marcha la Autoridad Plurinacional de la Madre Tierra, cuya estructura y funciones se encuentran reguladas por el Decreto Supremo 1696 de 2013. Sin embargo aún no se ha acometido la puesta en marcha de la Defensoría de la Madre Tierra (Diario Página Siete), falencia del gobierno boliviano bastante criticada, pues algunos consideran que este sería un mecanismo mucho más efectivo para la protección de los derechos de la Madre Tierra, que la gestión burocrática de una autoridad administrativa, tal como se ha evidenciado en países como Colombia con la Defensoría del Pueblo, protagonista de primer orden en temas como minería, explotación de hidrocarburos y contaminación de aguas. Adicionalmente algunos juristas con sobrada razón, objetan de la Ley 300 de 2012 boliviana, que solo otorgue legitimación para defender los derechos de la Madre Tierra a las autoridades públicas, jurisdiccionales y a las personas individuales o colectivas directamente afectadas, restringiendo el margen de acciones jurídicas y activismo ambiental (Pérez 2014), a diferencia de países como Ecuador y Colombia, donde cualquier persona sin necesidad de demostrar afectación directa de sus derechos al medio ambiente, la vida, la salud o la propiedad, puede interponer acciones legales para la defensa de los ecosistemas y los recursos naturales.

Por otra parte, el denominado extractivismo, entendido como la explotación intensiva de minerales e hidrocarburos e inclusive productos agrícolas con destino a los mercados globales (Gudynas 2010), sigue activo en la nación boliviana, pues aún se confía el rumbo de la economía nacional y el desarrollo de las políticas sociales y de bienestar en el marco de una visión progresista, a las divisas que aporten este tipo de exportaciones, más cuando el artículo 335 de la Constitución boliviana de 2009 consagra como prioridad del Estado la "industrialización y comercialización de los recursos naturales", premisa que contradice los avances jurídicos en materia de protección de los derechos de la Madre Tierra. La renegociación de contratos de hidrocarburos, la nacionalización de la industria, el impulso a la agricultura de monocultivo y la modificación de los gravámenes tributarios, buscando una mejor redistribución del ingreso y el fortalecimiento de políticas sociales y económicas de corte socialista (Gudynas 2012), alientan el nuevo modelo que en el fondo implica graves impactos de orden ambiental, pero que se extiende y consolida gracias a un modelo desarrollista del Estado boliviano, donde predomina la exportación de gas, minerales y otros recursos 
naturales ${ }^{11}$. En el caso de la agricultura, el gobierno apoyó fuertemente los monocultivos, en especial el de la soya, que hace uso de los controvertidos transgénicos (Solón 2016), negocio aún en manos de los antiguos terratenientes, que poco o nada fueron afectados por la reformas. En palabras de Solón (2016) que fue ministro de Estado de Bolivia:

La soya transgénica que en el 2005 representaba sólo el $21 \%$ de la producción de soya en Bolivia alcanzó el 92\% en el 2012. Se postergó la verificación del cumplimiento de la función económica social de las grandes propiedades que hubiera llevado a su expropiación y reversión, se perdonaron los desmontes ilegales de bosques y se llamó a ampliar la deforestación para beneficio fundamental de los agroexportadores...".

La confesión del estadista, uno de los grandes conocedores de la realidad social y ambiental boliviana, es bastante cruda; Bolivia se aferró al extractivismo y será muy difícil que abandone ese camino, pues se generan recursos que pueden ser dirigidos a financiar beneficios sociales, en una especie de estado de bienestar tercermundista, lo cual crea amplia aceptación popular y permite la continuidad del modelo de gobierno. El mea culpa continua:

Avanzar hacia una Bolivia agroecológica hubiera sido un camino mucho más acorde con el Vivir Bien y el cuidado de la Madre Tierra, pero ello no hubiera garantizado en lo inmediato cuantiosos ingresos económicos y hubiera significado una confrontación con la gran agroindustria soyera transgénica. (...)

El Vivir Bien y los derechos de la Madre Tierra cobraron notoriedad a nivel internacional pero a nivel nacional se fueron devaluando cada vez más porque sólo se limitaban a ser un discurso que no se ponía en práctica.

Por lo anterior, no sería atrevido decir que el país difícilmente abandonará o al menos no en el mediano plazo, el modo extractivista de producción, lastre fundamental para el desarrollo de los principios y acciones de contenido ecosocialista previstas en las leyes 071 de 2010 y 300 de 2012. En tal sentido surgen fuertes inquietudes sobre el futuro de un socialismo latinoamericano basado en la renta extractiva que genera grandes impactos en los sistemas naturales o que apela a los latifundios privados para garantizar la gestión de mega-monocultivos con el uso de transgénicos (López, 2016). En suma, la gran contradicción de la política

${ }^{11}$ Varios autores han hecho énfasis en el estado de cosas en Bolivia, donde el gobierno le apuesta a la explotación minera y de hidrocarburos y la agroindustria, como remedios contra la escasez de divisas y recursos financieros para el desarrollo. Sin embargo este tipo de actividades genera graves impactos ambientalescuyo manejo no está presente de manera clara en el discurso gubernamental. ambiental boliviana es la creación y promulgación un tanto ingenua y simbólica de normas de orden biocéntrico, cuya eficacia ha sido puesta en duda y su efectiva aplicación encuentra múltiples dificultades en el actual modelo de desarrollo, poco amigable con el principio del buen vivir y bajo el mandato de una Constitución antropocéntrica, jurídicamente de mayor jerarquía que las leyes de la Madre Tierra, que apuesta por el desarrollo sustentable y el estímulo a la producción para suplir las necesidades humanas (Molina 2014), sin que se haga una mínima alusión a los derechos propios de los sistemas naturales, contradicción jurídica de hondo calado, que puede generar inconvenientes a la hora de determinar la constitucionalidad de las disposiciones que otorgan derechos a la naturaleza, más cuando la presión del desarrollismo a ultranza y los intereses políticos podrían llegar a condicionar las decisiones judiciales ${ }^{12}$.

En el ámbito ecuatoriano, la preocupación por el desarrollo de los postulados naturalistas de la Constitución ha sido asumida de manera más consecuente, muestra de ello es el desarrollo de varios nichos de investigación sobre este nuevo fenómeno jurídico que convierte a la naturaleza en un sujeto de derechos. La misma Corte Constitucional ecuatoriana se ha encargado de difundir estudios sobre los nuevos derechos; investigaciones con interesantes y variados análisis sobre los derechos de la naturaleza salen a la luz, lo cual demuestra una real preocupación en el plano teórico, sobre la pertinencia y validez del biocentrismo jurídico. ${ }^{13}$

Adicionalmente algunas de las normas promulgadas recientemente, como el caso de la Ley Orgánica de los

\footnotetext{
${ }^{12}$ Después de la promulgación de la Constitución de 2009, hubo diferencias entrevarios movimientos indígenas bolivianos y el presidente Evo Morales debido al modelo de explotación de recursos naturales adoptadoporBolivia,llegándose a cuestionar fuertementelas nuevas leyes promulgadas por el Estado Plurinacional. Igualmentese hacía referencia al alejamiento del gobierno Morales de elementos importantes del indianismo que fueroncontemplados en la nueva Constitución. Ver SCHAVELZON, Salvador. El nacimiento del Estado Plurinacional de Bolivia. Etnografía de una Asamblea Constituyente. La Paz, CLACSO-CEJIS. 2012.

${ }^{13}$ Sobre el particular se recomiendan los textos sobre el nuevo constitucionalismo del Centro Ecuatoriano de Derecho Ambiental-CEDA en www.ceda.org. Ver también ACOSTA, Alberto y MARTINEZ Esperanza, (Edits.) Derechos de la Naturaleza. El futuro es ahora. Quito, Editorial AbyaYala, 2009, ACOSTA, Alberto y MARTINEZ Esperanza, (Comps.) La Naturaleza con Derechos. De la Filosofía a la Política. Quito, Ediciones AbyaYala, 2011; PRIETO MENDEZ, Julio. Derechos de la Naturaleza. Fundamento, contenido y exigibilidad jurisdiccional. Corte Constitucional del Ecuador. Quito 2013; GUDYNAS, Eduardo. El mandato ecológico: Derechos de la naturaleza y políticas ambientales en la nueva Constitución. Editorial AbyaYala, Quito, 2009.
} 
Recursos Hídricos y Uso y Aprovechamiento del Agua, del año 2014, incorporan entre sus principios la obligación de gestionar de manera integral el agua y adelantar acciones de recuperación y protección de este recurso con el fin de proteger los derechos de la naturaleza. En su artículo 64 de manera expresa dispone que "La naturaleza o Pacha Mama tiene derecho a la conservación de las aguas con sus propiedades como soporte esencial para todas las formas de vida", lo cual implica que la naturaleza tiene derecho a la protección de sus fuentes hídricas, el mantenimiento del caudal ecológico, la preservación de la dinámica natural del ciclo hidrológico, la protección de las cuencas hidrográficas y los ecosistemas, así como a su restauración, en palabras de la norma. Igualmente en la Ley Orgánica de Ordenamiento Territorial, Uso y Gestión del Suelo de 2016, se establece la categoría denominada "Suelo rural para aprovechamiento extractivo", que son áreas destinadas para actividades extractivas de recursos naturales no renovables "garantizando los derechos de naturaleza".

En el plano de la acción estatal encontramos varias contradicciones relevantes, pues el Ecuador le apuesta a la minería como actividad estratégica y una de sus principales fuentes de ingresos (Sacher \& Acosta 2012), además de ser conocidas las diferencias entre el Presidente Correa y la Asamblea de Montecristi al momento de discutir y redactar los principios fundantes de la Constitución ecuatoriana (Gudynas 2009). Es muy diciente que poco después de promulgarse la Constitución del Ecuador, se haya aprobado la Ley de Minería, que según algunos observadores busca fortalecer los proyectos mineros a gran escala y constituye un retroceso en materia de protección ambiental, (OCMAL 2015). Varios proyectos mineros de importancia han pasado al control directo del Estado a través de la Empresa Nacional Minera-ENAMI EP y de inversionistas chinos (OCMAL 2015). La iniciativa Yasuní, puesta en marcha en el año 2007, que buscaba obtener 3600 millones de dólares de la comunidad internacional en trece años, como compensación por la no explotación de unos 846 millones de barriles de petróleo en áreas del Parque Nacional Yasuní, en la Amazonía ecuatoriana, siendo un referente clave a nivel internacional sobre el compromiso ambiental de ese país, fue abandonada por el gobierno en el año 2013, debido al bajo recaudo obtenido; poco más de trece millones de dólares. El Presidente Correa, al sentenciar que el mundo le había fallado al Ecuador, anunció que la explotación de hidrocarburos en un área que equivalía a menos del 1\% del Parque Yasuní, representaba ingresos por más de 18000 millones de dólares, necesarios para disminuir los niveles de miseria de esa nación.

El panorama actual guarda similitudes con el caso boliviano; existe una fuerte dependencia del modelo extractivista, si bien en el Plan Nacional del Buen Vivir 2009-2013, se determinó que en el plazo de veinte años el país debía cambiar su matriz productiva para disminuir su dependencia del extractivismo ${ }^{14}$. Al igual que en Bolivia, el gobierno renegoció contratos petroleros, logrando mayores excedentes financieros y le apuesta fuerte a los hidrocarburos como fuente importante de divisas, a la vez que potencia la minería, así como el uso del recurso hidroenergético, lo cual ha generado conflictos sociales por el desplazamiento de comunidades para la construcción de las grandes represas y el temor a la disminución de los caudales (Ramírez \&Guijarro 2011). La contradicción entre las exigencias constitucionales del sumak kawsay o buen vivir y la protección de los derechos de la naturaleza, están a la orden de día en las protestas y movilizaciones de colectivos campesinos e indígenas contra el actual gobierno (Houtard 2015). La tensión entre el nuevo desarrollo de corte redistributivo y las demandas ambientales colectivas ponen en el centro de la discusión el pregonado nuevo estilo de vida (Ramírez\& Guijarro 2011) y no permiten ver un panorama totalmente claro en el desarrollo de los preceptos jurídicos respetuosos de la naturaleza.

En el escenario colombiano creemos que el camino por recorrer en relación con la protección de los derechos de la naturaleza aún es muy largo y que se requiere de mayores avances jurisprudenciales que refuercen los escasos fallos que se han proferido en esta materia. Sin embargo el lastre más importante es la ausencia de un principio constitucional que garantice estos derechos, panorama que será muy difícil de cambiar a la luz del modelo de desarrollo y del enfoque antropocéntrico de la Constitución Política, si bien existen propuestas bastantes interesantes en el plano teórico como el denominado Estado Ambiental de Derecho (MesaCuadros 2010), que propende por la superación del Estado Social de Derecho, buscando concretar la protección del medio ambiente como esencia y principio fundante de la acción estatal, con un claro respeto por los postulados democráticos y los derechos humanos.

${ }^{14}$ El Plan Nacional del Buen Vivir 2009-2013, recoge en buena parte las críticas al modelo neoliberal y al modo de acumulación y producción de bienes y capital, planteando las nuevas alternativas del Estado ecuatoriano en relación con la sostenibilidad ambiental y el logro de la justicia distributiva (Senplades 2009). El objetivo de este plan se centra en la protección de los derechos de la naturaleza y la promoción de un ambiente sano y sustentable introduciendo el concepto de biopluralismo que aludeque la actividad humana debe realizar un uso de los recursos naturales adaptado a la generación (regeneración) natural de los mismos. Igualmente el Plan Nacional del Buen Vivir 2013-2017, en su objetivo No. 7, continua los postulados de su antecesor en relación con la protección de los derechos de la naturaleza, planteando la evolución hacia una economía basada en la creación de conocimiento, que permita superar el modelo primario-exportador, bajo el lema de "usar el extractivismo para salir del extractivismo". Ver Plan Nacional para el Buen Vivir 2013-2017 pags. 82 y 418 (Senplades 2014). 
En ese orden de ideas, se deben celebrar los recientes fallos que le dan un nuevo aire al papel de los municipios en el control de la explotación y uso de los recursos naturales, como es el caso de la sentencia C-035 de 2016, que prohibe la minería en zonas de páramo y el ya clásico fallo del Consejo de Estado del año 2014 sobre el río Bogotá15, que constituye una pieza jurídica modelo a nivel nacional y una muestra de activismo judicial, el cual haciendo gala de un pragmatismo jurídico y ante la ineficiencia de las entidades estatales, toma decisiones puntuales para el control de la contaminación de las aguas y prácticamente impone políticas públicas de gestión del recurso hídrico, lo que ha generado cierto escozor en ámbitos académicos y judiciales que critican la injerencia de los jueces en esferas propias de la Administración (Guzmán 2014). Esta nueva ola jurisprudencial hace énfasis en la protección de los ecosistemas vitales para el país, supone un mayor control de la institucionalidad pública ambiental, garantiza el principio de participación ciudadana y refuerza la autonomía de las entidades territoriales en lo referente a la gestión, defensa y conservación de su patrimonio ecológico, elementos indispensables y punta de lanza de una esfera pública ambiental enfocada hacia el enverdecimiento de la política y del mismo Estado, que en últimas es uno de los objetivos comunes del nuevo biocentrismo.

Sin embargo es importante tener en cuenta que en muchos países de la región la gestión ambiental y las preocupaciones ecológicas aún se discuten y resuelven en gran parte en las manos del Estado Administrativo (Paelhke- Torgerson 2005), el viejo Leviathan, mal necesario y común a una enorme mayoría de países, representado por las burocracias profesionales administradoras de los recursos naturales, las agencias de control de la contaminación, los instrumentos de política regulatoria ambiental, el proceso de evaluación de impacto ambiental y las técnicas de análisis basadas en una política racionalista (Dryzek 2005), que poco a poco se refuerza con más y más dependencias, divisiones, subdirecciones y coordinaciones y depende a diario de resoluciones, circulares, instructivos, procedimientos y memorandos, cuando no de la discrecionalidad de sus funcionarios, por lo que la gestión ambiental termina diluida en un entramado detrámites y actuaciones con poco o mínimo efectosobre la salud y vitalidad del patrimonio natural.

En consecuencia, otro de los grandes retos del nuevo biocentrismo jurídico que ya de entrada enfrenta un modelo de desarrollo económico extractivista, es el replanteo de las

${ }^{15}$ Consejo de Estado. Sala de lo Contencioso Administrativo, Sección Primera, 28 de marzo de 2014, M.P. Marco Antono Velilla Moreno, Exp. AP-25000-23-27-000-2001-90479-01 estructuras administrativas que permean la acción ecológica del Estado; esta modernización ecológica que ha operado en otras latitudes (Mol 1998) e implica reformas de orden institucional con la colaboración de las agencias estatales,la industria, la ciudadanía y los movimientos sociales, debe hacerse progresivamente en el ámbito latinoamericano y en especial en aquellos países que le apuestan a los nuevos derechos de los no humanos, como medio de proteger su herencia natural, pero dentro del marco del diálogo y puntos de encuentro entre las cosmovisiones y principios originarios que alientan los nuevos modelos de vida y la racionalidad que marca de manera predominante la acción estatal.

\section{CONCLUSIONES}

Los derechos de la naturaleza son un nuevo y revolucionario referente jurídico en América Latina, logrado en gran parte por la conjunción de movimientos sociales basados en la de colonización y en una apertura jurídica en contraposición a la clásica visión del derecho ambiental dominante en la mayor parte del hemisferio. Estos derechos contraponen una visión biocéntrica que reclama consideración moral para los seres vivos no humanos y los sistemas naturales, al clásico enfoque antropocéntrico de las normas que regulan la protección del medio ambiente ylos recursos naturales. Sin embargo, la efectivización de estos nuevos derechos debe trascender el fuerte simbolismo asociado y la retórica que rodea su fundamentación para concretarse en acciones puntuales de protección del patrimonio ecológico que consideren los demás derechos y prerrogativas de los seres humanos.

El reconocimiento de los derechos de la naturaleza no es un logro novedoso y original del constitucionalismo ambiental latinoamericano del siglo XXI, ni del nuevo derecho ecologista que ha adquirido gran importancia en países como Ecuador y Bolivia. Este enfoque biocéntrico de las normas ya ha tenido manifestaciones muy aproximadas en las leyes ecológicas de régimen nazi, aunque en un escenario ideológico, político y social totalmente diferente y también ha sido consagrado de manera expresa en las ordenanzas municipales de más de 30 localidades en los Estados Unidos, que desde el año 2006 vienen reconociendo derechos a los ríos, los arroyos, los humedales, las comunidades naturales y los ecosistemas, en un claro ejercicio de autogobierno preventivo que según sus inspiradores se funda en los principios democráticos de la Constitución norteamericana, si bien es de orden más bien pragmático, careciendo del simbolismo y la retórica biocéntrica fuerte utilizada en países como Ecuador y Bolivia 
El gran avance de la legislación biocéntrica en Latinoámerica, que establece las más amplias garantías para la protección de la naturaleza, al darle la categoría constitucional y legal de sujeto con derechos, representa en el siglo XXI el máximo grado de evolución de las normas ecológicas a nivel mundial. El reconocimiento de la naturaleza como nuevo sujeto jurídico, asume un difícil reto frente a los esquemas tradicionales de gestión del patrimonio natural y pone sobre la mesa un nuevo elemento de discusión que debe ser dilucidado por los juristas y los políticos en conjunto con la sociedad civil, en el entendido de que estos derechos no deben estar sujetos a las variaciones del escenario político, para que su eficacia no sea meramente simbólica y sucumban fácilmente a los embates de un modelo de desarrollo extractivista.

En el caso de Bolivia, es evidente la contradicción entre los principios y lineamientos referidos a la Madre Tierra y a su reconocimiento como sujeto colectivo de derecho en las Leyes 071 de 2010 y 300 de 2012, frente a los principios de la Constitución de 2009, que obligan al Estado a fomentar y apoyar la industrialización y comercialización de los recursos naturales y no reconocen a la Madre Tierra como un sujeto de derechos. Esta contradicción puede traer importantes consecuencias a la hora de interpretar el verdadero alcance de estas normas en el marco de una norma de mayor jerarquía como es la Constitución.

Gran parte del aparato institucional a cargo de la aplicación y garantía de los nuevos derechos de la naturaleza, está creado a nivel normativo, por lo que se hace necesaria la inversión de recursos financieros para el rediseño y fortalecimiento de un verdadero sistema administrativo que pueda hacer frente al enorme reto que implica el reconocimiento y efectiva protección de los derechos de la naturaleza o la Madre Tierra.

Los fallos judiciales que decidan sobre la protección de los derechos de la naturaleza, deben ponderar igualmente la necesidad de desarrollo económico y social, generando paulatinamente interpretaciones mucho más elaboradas de estos derechos, bajo una visión integral de la nueva legislación, que considere la realidad sociopolítica y la urgencia de garantizar el desarrollo humano absolutamente respetuoso de la naturaleza, reconociendo desde el ámbito biocéntrico que los seres humanos somos un componente más del gran sistema natural.

\section{REFERENCIAS}

ACOSTA, A. \& MARTINEZ E. 2009 (Edits.) Derechos de la Naturaleza. El futuro es ahora. Editorial AbyaYala, Quito. $122 \mathrm{pp}$.

ACOSTA, A. \& MARTINEZ E. 2011 (Comps.) La Naturaleza con Derechos. De la Filosofía a la Política. Ediciones AbyaYala, Quito. 376 pp.

AMAYA, O. D. 2002. La Constitución Ecológica de Colombia.Universidad Externado de Colombia, Bogotá D.C. 2002.

BERRY, T. 1999. The Great Work: Our Way into the Future. Bell Tower; New York.241 pp.

BONILLA, D. 2015. La Economía política del pensamiento jurídico. Revista de Estudos Empíricos em Direito. Brazilian Journal of Empirical Legal Studie vol. 2, n. 1, jan 2015, p. 2659. (Fecha deacceso 3 de diciembre de 2016). URL disponible en:www.reedrevista.org.

BORDIEU P. WACQUANT L. 2001 Las Argucias de la Razón Imperialista. Paidos Ibérica, Madrid.54 pp

CELDF. 2008. Press Release: Ecuador Approves New Constitution: Voters Approve Rights of Nature.URL disponible en: http:/ / www.celdf.org/article.php?id=302

CLOSMANN, Ch. 2005.Legalizing Volksgemeinschaft. Nazy Germany's Reich Nature Protection Law of 1935.En BRUGGEMEIER, F. G., CIOC M. \& ZELLER T. (eds).How Green were the Nazis:18-42.Ohio University Press, Athens. 283 pp.

CONSEJO DE ESTADO 2012. Sentencia dela Sala de lo Contencioso Administrativo, Sección Tercera, Subsección C Consejero ponente: ENRIQUE GIL BOTERO Bogotá D.C., veintitrés (23) de mayo de dos mil doce (2012)Radicación número: 17001-23-3-1000-1999-0909-01(22592).

CONSEJO DE ESTADO 2013. Sentencia de la Sala de lo Contencioso Administrativo, Sección Tercera, Subsección C Consejero ponente: ENRIQUE GIL BOTERO. Bogotá, D.C., veintiséis (26) de noviembre de dos mil trece (2013)Número de Radicación: 25000-23-24-000-2011-00227-01(AP).

CONSEJO DE ESTADO 2014. Sentencia de Sala de lo Contencioso Administrativo, Sección Primera, 28 de marzo de 2014, M.P. Marco Antonio Velilla Moreno, Exp. AP25000-23-27-000-2001-90479-01. 
CORTE CONSTITUCIONAL, 2011. Sentencia de constitucionalidad C-632 del 24 de agosto de 2011. M.P. Gabriel Eduardo Mendoza Martelo, Exp.D-8379.

CORTE CONSTITUCIONAL 1992. Sentencia de tutela T-411 de del 17 de junio de 1992, M.P. Alejandro Martínez Caballero. Exp. T-785

CORTE CONSTITUCIONAL 1994. Sentencia de constitucionalidad C-058 del 17 de 1994, M.P. Alejandro Martínez Caballero. Exp.N D-369.

CULLINAN, C. 2011. Wild Law.A manifesto for the Earth Justice. Second Edition, Green Books, Devon. 206 pp.

DEVALL, B. \& SESSIONS, J. 2004.Ecología Profunda. En VALDEZ C. (comp.) Naturaleza y Valor: 2225-236.Fondo de Cultura Económica, México D.F.

DIARIO PÁGINA SIETE. Tras 6 años de la 071, aún no hay la Defensoría de la Madre Tierra. (Fecha de acceso 4 de noviembre de 2016). URLdisponible en:http://www.paginasiete.bo/nacional/2016/2/29/trasanos-071-defensoria-madre-tierra-88232.html.

DOBSON, A. 1997. Pensamiento Político Verde.Paidós Editores,Barcelona. 268 pp.

-DRYZEK, J. 2005. The Politics of the Earth. Environmental Discourses, Second Edition, Oxford University Press, New York .261 pp.

ELBERS, J \& MUÑOZ G. 2012. Transiciones en el Ecuador: de la nueva Constitución hacia un paradigma holístico. En ALAYZA A. y GUDYNAS E. (Edits) Transiciones y alternativas al extractivismo en la región andina. Una mirada desde Bolivia, Ecuador y Perú: 47-74. Centro Peruano de Estudios Sociales-CEPES,Lima.

CABA, S \& GARCIA, G. 2014. La denuncia al eurocentrismo en el pensamiento sociallatinoamericano y la problemática de la universalidad del conocimiento. Polis Revista Latinoamericana No. 38/2014. Pueblos Indígenas y Descolonización. (Fecha de acceso 9 de noviembre de 2016). URL disponible en: http:// polis.revues.org/10024.

CANAL, F. 2007.Elementos de Análisis para la Evaluación y ajuste de lasCorporaciones AutónomasRegionales y de DesarrolloSostenible. Documento de Políticas PúblicasNo.14, Foro Nacional Ambiental, Bogotá D.C.

FERRY, L. 1994. El Nuevo Orden Ecológico. Editorial Tusquets, Barcelona.231 pp.
GIRALDO, L F. 2012. El discurso moderno frente al "pachamamismo": La metáfora de la naturaleza como recurso y el de la Tierra como madre. Polis Revista Latinoamericana, No. 33/2012. Hacia la construcción de un nuevo paradigma social. (Fecha de acceso 25 de octubre de 2016).URL disponible en:http:/ / polis.revues.org/ 8502.

GUDYNAS, E.2010. Diez Tesis Urgentes sobre el nuevo extractivismo. (accesado el 26 de octubre de 2016).Disponible www.Ambiental.net/.../GudynasNuevoExtractivismo10.

GUDYNAS, E. 2009. El Mandato Ecológico. Editorial AbyaYala, Quito . 208 pp.

GUDYNAS, E. 2012. Estado Compensador y Nuevos Extractivismos. Las ambivalencias del progresismo sudamericano. Revista Nueva Sociedad, No. 237.URL disponible en:htto:/www.gudynas.com/publicaciones/artículos/Gud ynasEstadoCompensadorNvaSociedad12.pdf. pp.128-146.

GRAHAM, N. 2003.Lawscape: Paradigm and Place in Australian Property Law, University of Sydney.Cit. por BURDON, P. Wild Law The philosophy of Earth Jurisprudence Alternative Law Journal 62.(Fecha de acceso 26 de octubre de 2016). URLdisponible en:http://www.austlii.edu.au/au/journals/AltLawJl/2010 /21.html.

GUZMÁN, L. 2014 Las aguas residuales en la jurisprudencia del Consejo de Estado. Período 2003-2014.Universidad Externado de Colombia,Bogotá D.C.96 pp.

HABERMAS, J. 1986. Ciencia y Técnica como Ideología. Editorial Tecnos. Madrid. 112 pp.

HOUTARD, F. 2015.El agotamiento de un modelo en crisis mundial. (Fecha de acceso 30 de octubre de 2016).Disponible en http:/ / www.rebelion.org./noticia.php.?id=202575.

-IMORT, M., 2005. Eternal Forest-Eternal Volk. The retoric and Reality of National Socialist Forest Policy.En BRUGGEMEIER, F. G., CIOC M. \& ZELLER T. (eds).How Green were the Nazis:43-72. Ohio University Press, Athens. $283 \mathrm{pp}$

KOONS, J. 2008 Earth Jurisprudence. The moral value of Nature.Pace Environmental Law Review, Vol. 25 (Fecha de acceso 10 de noviembre de 2016).URL disponible en: http:/ / ssrn.com/abstract=1824961. 
Ambiente y Sostenibilidad 2016 (6): 64-79

Revista del Doctorado Interinstitucional en Ciencias Ambientales

ISSN: 2339-3122

LOVELOCK, J. 1995. Las Edades de Gaia. 2 Ed., Tusquets, Barcelona.

LOVELOCK, J. 2011 La Tierra se Agota. Editorial Planeta, Barcelona.291 pp.

LÓPEZ, S. 2016. Problemas y desafíos económicos del socialismo en la América Latina del siglo XXI: Cuba, Venezuela, Ecuador y Bolivia. ALAINET (Fecha de acceso 30 de septiembre de 2016). URL disponible en: http://www.alainet.org/es/articulo/179852.

MESA-CUADROS, G. 2010. Derechos ambientales en perspectiva de integralidad. Concepto y fundamentación de nuevas demandas y resistencias actuales hacia el Estado ambiental de derecho. Universidad Nacional, Bogotá.566 pp.

MOL, A. 1998. Modernización Ecológica. Transformaciones Industrialesy Reforma Medioambiental. En REDCLIFT M. \&WOODGATE G.(Coords), Sociología del Medio Ambiente: 143-156. McGraw Hill, Madrid.

MOLINA, J. 2014. Derechos de la Naturaleza. Historia y Tendencias Actuales. Universidad Externado de Colombia, Bogotá D.C. 221 pp.

NATTRASS, K. 2004. "Und die tiere".Constitutional Protection for Germany's Animals. Animal Law Review at Lewis\& Clark Law School . Vol. 10, 283-312. (Fecha de acceso 2 de diciembre de 2016). URL disponible en: https://www.animallaw.info/article/und-die-tiereconstitutional-protection-germanys-animals

PAEHLKE, R. \&TORGERSON D. 2005.Environmental Politics and the Administrative State.En PAEHLKE R. \&TORGERSON D. (Edits.) Managing Leviathan. Environmental Politics and the Administrative State: 313326. Broadview Press, Toronto. 351pp.

PÉREZ, A. Derechos de la Madre Tierra: ¿Quién tiene capacidad para defenderlos?. Revista Nueva Crónica y Buen Gobierno (Fecha de acceso 4 de noviembre de 2016). URL disponible

en:http://www.nuevacronica.com/sociedad/derechos-dela-madre-tierra-quien-tiene-capacidad-para-defenderlos/.

PRIETO-MENDEZ, J. 2013. Derechos de la Naturaleza. Fundamento, contenido y exigibilidad jurisdiccional. Corte Constitucional del Ecuador. Quito. 279 pp.

OBSERVATORIO DE CONFLICTOS MINEROS EN AMERICA LATINA-OCMAL. 2015. Conflictos mineros en América Latina: Extracción, saqueo y agresión - Estado de

situación en 2014.(Fecha de acceso 8 de noviembre de 2016).URL en:www.conflictosmineros.net/agregardocumento/publicaciones-ocmal/.

OST, F. 1996. Naturaleza y Derecho. Bilbao, Ediciones Mensajero. 333 pp.

RADKAU, J. 2008.Nature and Power. A Global History of the Environment.Cambridge University Press,WashingtonNew York. 430 pp.

RAMIREZ, F. \& GUIJARRO, J. 2011.Ecuador: conflicto social y cambio político en el Ecuador del siglo XXI. CEPRID. (Fecha de acceso 2 de septiembre de 2016).URL disponible en: http://www.cetri.be/Conflicto-social-y-cambiopolitico?lang $=\mathrm{fr}$.

REES, A. 2007. Auschwitz. Los Nazis y la Solución Final. Editorial Crítica, Barcelona.368 pp.

RODRIGUEZ, G. A. 2012. La Consagración de los Derechos Ambientales en las Constituciones Políticas de Colombia, Ecuador y Bolivia. En RODRIGUEZ G. A. \& PAEZ I. A.(eds) Temas de Derecho Ambiental. Una mirada desde lo público: 1-54. Universidad del Rosario, Bogotá D.C.

SACHER, W. ACOSTA, A. 2012. La Minería a gran Escala en Ecuador. Análisis y datos estadísticos sobre la minería industrial en el Ecuador. Editorial AbyaYala.Quito, 2012.

-SAX, B., 2000. The Animals in the Third Reich. Pets, Scapegoats and the Holocaust., Continuum International Publishing Group, New York. 234pp.

SCHAVELZON, S.2012. El nacimiento del Estado Plurinacional de Bolivia. Etnografía de una Asamblea Constituyente. CLACSO-CEJIS. La Paz. 623 pp.

-SENPLADES. 2009. Plan Nacional para el Buen Vivir 20092013: Construyendo un Estado Plurinacional e Intercultural, Quito.

-SENPLADES. 2013. Plan Nacional para el Buen Vivir 20132017: Todo el mundo mejor(fecha de acceso 16 de diciembre de 2016). URL disponible en www.buenvivir.gob.ec

SOLON, P. 2016.Algunas reflexiones, autocríticas y propuestas sobre el proceso de cambio en Bolivia. URL disponible en:https:/ / pablosolon.wordpress.com/2016/02/25/algunasreflexiones-autocriticas-y-propuestas-sobre-el-proceso-de-cambio/.

SUAREZ, S. 2012. Efectivización de los derechos de la Naturaleza.Boletín del Centro Ecuatoriano de Derecho 
Ambiental. No. 27 (Fecha de acceso 11 de noviembre de 2016). URL disponible en: www.ceda.org.ec.

SUNSTEIN, C. 2002. The Rights of Animals: A Very Short Primer. University of Chicago Public Law \& Legal Theory Working Paper No. 30. (Fecha de acceso 5 de diciembre de 2016).URL disponible en: http://ssrn.com/abstract_id=323661.

UEKOETTER, F. 2006. The Green and the Brown. A History of Conservation in Nazy Germany. Cambridge University Press,New York. 230 pp.

VANHULST, J. \& BELING, A. 2013. El Buen vivir: una utopía latinoamericana en el campo discursivo global de la sustentabilidad. Polis Revista Latinoamericana Vol. 12 No. 36. (Fecha de acceso 8 de noviembre de 2016).URL disponible en: https:// polis.revues.org/9638.

WOLSCHKE-BULMAHN, J.2005.Violence as the Basis of National Socialist Landscape Planning in the "Annexed Eastern Areas".En BRUGGEMEIER, F. G., CIOC M.\& ZELLER T. (eds).How Green were the Nazis:243-256. Ohio UniversityPress, Athens. 283 pp.

ZAFFARONI, E. 2011 La Pachamama y el Humano. En ACOSTA A. \& MARTINEZ E. (comps) La Naturaleza con Derechos. De la Filosofía a la Política: 25-137. Ediciones AbyaYala, Quito. 367 pp. 